\title{
PENENTUAN JUMLAH OPERATOR BAGIAN PACKING DENGAN MENGGUNAKAN METODE ANTRIAN GUNA MENGURANGI WAKTU TUNGGU DAN BIAYA
}

\author{
Teguh Baroto ${ }^{1}$, Ayudina Puji $\mathbf{E}^{2}$
}

\begin{abstract}
The queue in packing division PT. Domusindo Perdana caused of product arriving that will be packed over than service facilities available so that long queuing happened and it makes long waiting time that will be caused to high totally cost.

Alocation of operator number in packing division that have lot of queue is in Centre of Panel (1 person), Base Assembly (1 person), Drawer Side, Back, Base (1 person) and strawpack (4 persons) after analysis of queuing. Using searching analysis of optimum working number, will increase operator in Centre Panel Devision ( 3 person), Base Assembly ( 3 persons), Drawer Side, Back, Base (4 persons) and strapack ( 5 person) to make these divisions don't have any queue.

The increasing of service facilities in packing division from the initial condition 7 persons / operator and in end condition about 15 operators. Overall cost spent everyday decrease about Rp. 117.471.214, 00 than the initial condition Rp. 245.675.136, 00 and the last condition Rp. 67.193.922 with overall waiting time in packing division decrease about 25.20 minutes than the initial condition about 39.6 minutes to 14.4 minutes. .
\end{abstract}

Key Words : Queue, Waiting time, Server, Operator

PENDAHULUAN

PT Domusindo Perdana merupakan perusahaan manufaktur yang memproduksi furniture. Bahan bakunya berasal dari kayu mahogany, pinus, mindi dan lain-lain yang berorientasi eksport dengan pangsa pasar Amerika serikat (Sebesar $81 \%$ ). Sifat produksinya adalah Job order, dimana buyer memesan produk sesuai dengan yang mereka kehendaki.

Dampak yang dialami oleh PT Domusindo Perdana dengan menurunnya Jumlah permintaan yang tidak menentu (dapat dilihat dilampiran ) adalah terjadinya pengurangan sejumlah operator diseluruh stasiun kerja ( WorkStation) terutama di bagian packing. Packing merupakan salah satu rute produksi akhir dari proses produksi
Dibagian packing terjadi tiga tahapan, yaitu Pra strapack artinya komponen yang terdiri dari center panel, Base assembly, Door Panel, Drawer Front Drawer side, Back, dan assembly dibungkus dengan $\mathrm{PE}$ foam (gabus Tipis). Strapack artinya kumpulan dari beberapa komponen yang telah dipra strapack diikat menjadi satu. Packaging artinnya pengepakan komponen dari satu produk beserta hardware ke dalam karton boxs.

Jika dilihat dibagian packing, Hubungan antara tahapan packing sebagai satu kesatuan sistem aliran kerja dengan fasilitas pelayanan (server) pada masingmasing Work station terhadap kelancaran aliran proses kurang begitu baik karena terlihat pada penempatan jumlah operator yang kurang efektif. Dikatakan kurang 
efektif karena operator ( server ) yang hanya menangani proses packing dengan satu macam produk dialihkan kebeberapa proses packing dengan produk lain yang akan segera ( urgent ) untuk dieksport. Hal ini menyebabkan tidak adanya keseimbangan antara produk yang akan dipacking ( customer ) dengan fasilitas pelayanan ( operator ) yang banyak menimbulkan antrian sehingga waktu tunggu menjadi lama dan berdampak pada biaya yang tinggi.

\section{TINJAUAN PUSTAKA}

\section{SISTEM ANTRIAN}

Pada dasarnya teori antrian merupakan pengembangan model antrian dalam menentukan jumlah yang optimal dari fasilitas telepon switching yang digunakan untuk melayani demand yang ada. Teori antrian pertama kali dirintis oleh seorang Insinyur dan seorang ahli matematika berkebangsaan Denmark yang bernama $A . K$ Erlang diawal tahun 1900-an. Sistem antrian yang terjadi didalam kehidupan sehari-hari merupakan garis tunggu dari satuan pelanggan yang memerlukan pelayanan satu atau lebih fasilitas pelayanan. Kejadian garis tunggu timbul dikarenakan oleh kebutuhan akan layanan melebihi kemampuan pelayanan atau fasilitas pelayan sehingga pelanggan yang tiba tidak bisa segera mendapatkan layanan disebabkan kesibukan pelayanan.

Sebenarnya tujuan dasar sebuah model antrian adalah mencapai keseimbangan antara ongkos pelayanan dengan ongkos yang disebabkan adanya waktu tunggu (cost of waiting) dengan cara meminimumkan biaya yang berupa biaya langsung penyediaan fasilitas pelayanan dan biaya tidak langsung karena pelanggan harus menunggu untuk segera dilayani. Sistem antrian yang terjadi dapat bersifat kompleks atau sederhana. Sistem antrian yang sederhana dapat diselesaikan dengan menggunakan analisa antrian berupa struktur model antrian dan sistem antrian yang kompleks diselesaikan dengan analisa simulasi .

\section{Disiplin Antrian}

Disiplin antrian merupakan kebiasaan dalam memilih pelanggan dari antrian untuk segera dilayani.

Disiplin antrian yang biasa digunakan adalah:

- FIFO ( First In First Out) ata $u$ FCFS ( First Come Fisrt Served )

Artinya pelanggan datang pertama dilayani pertama.

- $L I F O$ ( Last In First Out) atau LCFS ( Last come First Served)

Artinya pelanggan yang datang terakhir dilayani pertama.

- $\operatorname{SIRO~(~service~In~Random~Order~)~}$

Artinya pelayanan dilakukan secara acak.

口 PS ( Priority service)

Artinya pelayanan dilakukan dengan tingkatan prioritas tertentu terhadap pelanggan. 
Model Struktur antrian dasar yang terjadi dalam sistem antrian

\section{ㄴ Single Channel-Single Phase}

Sistem ini yang paling sederhana. Single channel berarti hanya ada satu jalur untuk memasuki sistem pelayanan ( ada satu sistem pelayanan). Single phase berarti hanya ada satu stasiun pelayanan ( sekumpulan tunggal operasi yang dilakukan). Setelah mendapat pelayanan, pelanggan keluar dari sistem. Contoh : seorang tukang cukur, pembelian tiket kereta api yang dilayani oleh satu loket.

\section{- Single Channel-Multi Phase (Seri)}

Multi Phase menunjukkan dua / lebih pelayanan yang dilaksanakan secara berurutan (dalam phase). Contohnya lini produksi, pencucian mobil, tukang cat dan sebagainya.

\ Multi Channel - Single Phase (Pararel)

Sistem ini terjadi bila ada dua / lebih fasilitas pelayanan yang dialiri oleh antrian tunggal. Contohnya pembelian tiket yang dilayani oleh lebih dari satu loket, pelayanan potong rambut, oleh beberapa tukang rambut dan sebagainya

․ Multi channel - Multi Phase ( Seri Pararel)

Sistem ini dalam setiap tahapnya mempunyai beberapa fasilitas pelayanan ( Server ) sehingga lebih dari satu pelanggan yang dilayani pada suatu waktu.. Jaringan ini terlalu kompleks untuk dianalisa dengan teori antrian sehingga biasanya digunakan analisa simulasi. Contohnya pembayaran herregistrasi, pelayanan pasien dirumah sakit dari mulai pendaftaran, diagnosa, penyembuhan sampai pembayaran.

\section{Notasi dan simbol yang digunakan dalam sistem antrian}

Notasi baku dalam sistem antrian pada awalnya dirancang oleh D.G Kendall pada tahun 1953 dalam bentuk ( a / b / c ) yang dikenal sebagai " notasi Kendall”.

Alasan digunakan notasi ini adalah :

- Notasi tersebut merupakan alat yang efisien untuk mengidentifikasikan model antrian

\ Banyak buku yang menggunakan notasi ini

Model ini diklasifikasikan kedalam notasi :

$$
(\mathrm{a} / \mathrm{b} / \mathrm{c}) ;(\mathrm{d} / \mathrm{e} / \mathrm{f})
$$

Dimana :

a. : Distribusi kedatangan

b. : Distribusi waktu pelayanan

c. : Jumlah pelayan pararel $(c=1,2,3, \ldots \ldots, \infty)$

d. : Peraturan pelayanan ( misalnya : FIFO, LIFO, SIRO, PS )

e. : Jumlah maksimum yang diijinkan dalam sistem

f. : Ukuran sumber pemanggilan

Notasi baku pengganti $a \quad \& \quad b$ untuk kedatangan dan keberangkatan dengan kode:

M : Distribusi kedatangan (poisson)

Distribusi keberangkatan (eksponensial) juga sama dengan 
distribusi antara kedatangan eksponensial atau distribusi waktu pelayanan adalah eksponensial.

D :Waktu antar kedatangan atau waktu pelayanan yang konstan atau deterministic

$\mathrm{G}$ : Distribusi umum waktu keberangkatan atau waktu pelayanan

Untuk huruf $c$ merupakan bilangan positif untuk menyatakan jumlah pelayanan pararel. Oleh A.M. Lee ditambahkan symbol $d$ sebagai kode pengganti

FIFO atau FCFS : First In First Out atau First Come Fisrt Served

LIFO atau LCFS : Last In First Out atau Last come First Served

$\begin{array}{ll}\text { SIRO } & \text { : Service In Random } \\ & \text { Order } \\ \text { PS } & \text { : Priority service }\end{array}$

Untuk huruf $e$ dan $f$ dipergunakan kode $N$ atau menyatakan jumlah terbatas atau tak terbatas satu - satuan dalam sistem antrian dan populasi masukan.

\section{Model Waktu Tunggu}

a. Untuk saluran Ganda (M/M/C) : (GD / /

$\sim)$

$>$ Waktu rata-rata menunggu dalam Sistem $(\mathrm{W}=\mathrm{E}(\mathrm{Tt}))^{4}$

$E(T t)=f b\left(\frac{1}{c \mu-\lambda}\right)+\frac{1}{\mu}$

\section{Dimana :}

fb : Peluang masa sibuk untuk saluran ganda (nilai dari tabel probability of a busy period )
C : Jumlah server
$\lambda$ : Rate kedatangan
$\mu$ : Rate pelayanan

Waktu rata-rata menunggu dalam Antrian $(\mathbf{W q}=\mathbf{E}(\mathrm{Tw}))^{\mathbf{5}}$

$$
E(T w)=f b\left(\frac{1}{c \mu-\lambda}\right)
$$

Dimana :

$\mathrm{Fb}$ : Peluang masa sibuk untuk saluran ganda (nilai dari tabel probability of a busy period )

C : Jumlah server

$\lambda$ : Rate kedatangan

$\mu$ : Rate pelayanan

\section{Untuk saluran Tunggal}

$>$ Waktu rata-rata menunggu dalam Sistem $(W=E(T t))^{6}$

$$
E(T t)=\frac{\lambda}{\mu}\left(\frac{1}{\mu-\lambda}\right)+\frac{1}{\mu}
$$

$>$ Waktu rata-rata menunggu dalam Antrian ( $\mathbf{W q}=\mathbf{E}(\mathrm{tw}))^{7}$

$$
E(T t)=\frac{\lambda}{\mu}\left(\frac{1}{\mu-\lambda}\right)
$$

\section{METODOLOGI PENELITIAN}

\section{Data yang Diperlukan}

Data-data yang dikumpulkan antara lain: Data Waktu antar Kedatangan, Data Waktu Pelayanan, Data tentang Biaya Langsung, Biaya Operator, Biaya overhead ( Production Cost ), Biaya tidak Langsung (Common Cost), Data Demand, serta Layout Packing. 


\section{Tahap Pengolahan Data}

Data yang diperoleh kemudian diolah dengan menggunakan beberapa tahap yaitu :

$>$ Pengujian Distribusi

$>$ Analisa Antrian

\section{HASIL DAN PEMBAHASAN}

Pengolahan data dilakukan guna pemecahan masalah sesuai dengan tujuan yang diharapkan.

\section{Biaya yang terjadi antara lain :}

\section{a. Biaya Langsung}

* Gaji operator Tetap dan Kontrak

- 1 Shift hari kerja $=8$ jam / hari

- 1 Minggu $=40$ jam kerja ( 5 hari kerja)

- Rata - rata gaji / bulan Rp 600.000,-

- Untuk Gaji 1 minggu sebesar Rp 150.000,-

- 1 Bulan 25 hari kerja

* Biaya overhead dibagian Packing sebesar Rp 1.980.000 / hari.

Jumlah operator ( server ) tetap dan kontrak dibagian packing sebanyak 1 lorang yang mana terbagi atas :

- 6 operator dibagian Prastrapack

- 4 operator dibagian strapack

- 1 operator dibagian packaging

Biaya yang dikeluarkan oleh perusahaan untuk I group ( 11 operator ) :

$=($ jumlah operator $\mathrm{x}$ Gaji operator $)+$ Biaya overhead
$=(11 \times \operatorname{Rp} 30.000)+\operatorname{Rp} 1.980 .000$

$=\operatorname{Rp} 2.310 .000$,-

$\mathrm{C}_{1}=$ Gaji operator + Biaya Overhead

$=$ Rp. $30.000,-+$ Rp. 1.980.000,-

$=$ Rp. 2.010.000,-

* Ada 2 Shift Kerja

- Shift I

Pukul 7.00 - 15.00 Wib untuk

Hari Senin - Jum'at

- Shift II

Pukul 19.30 - 3.30 Wib untuk

Hari Senin - Kamis

Pukul 20.00 - 4.00 Wib untuk

Hari jum'at

\section{b. Biaya Tidak Langsung}

* Kapasitas produksi Changing Tower Perusahaan sebesar 110 Set / hari

- Produksi Changing Tower :

$$
\begin{aligned}
& =\frac{110 \mathrm{Set} / \mathrm{Hari}}{8 \mathrm{jam} / \mathrm{Hari}} \\
& =13.75 \mathrm{Set} / \mathrm{jam} \approx 14 \mathrm{set} / \mathrm{jam}
\end{aligned}
$$

* Downtime ditetapkan Perusahaan sebesar $15 \%$

Keuntungan bersih rata-rata produk Changing Tower Rp 342.000 / Set

Keuntungan Produksi / jam:

$$
\begin{aligned}
& =14 \mathrm{Set} / \mathrm{jam} \times 342.000 / \mathrm{Set} \\
& =R p 4.788 .000 / \mathrm{jam}
\end{aligned}
$$

Biaya Tidak Langsung $\left(C_{2}\right)$

$=$ Keuntungan produksi/ jam $x$ Downtime

$=R p 4.788 .000 \times 0.15$

$=R p 718.200 / \mathrm{jam}$ 


\section{Pengujian Distribusi}

Tabel 1

Hasil Pendugaan Awal Distribusi untuk Waktu Antar Kedatangan Changing Tower (menit)

\begin{tabular}{|c|l|c|c|}
\hline No & \multicolumn{1}{|c|}{ JENIS DATA } & $\begin{array}{c}\text { DISTRIBUSI } \\
\text { AWAL }\end{array}$ & - \\
\hline 1 & Pra-Strapack Center Panel & Eksponensial & 1.93731 \\
\hline 2 & Pra-Strapack Bass Assembly & Eksponensial & 1.23483 \\
\hline 3 & Pra-Strapack Door Panel & Eksponensial & 6.78523 \\
\hline 4 & Pra-Strapack Drawer Front & Eksponensial & 6.61202 \\
\hline 5 & Pra-Strapack Drawer Side, Back dan Base & Eksponensial & 3.12176 \\
\hline 6 & Hardware & Eksponensial & 5.22937 \\
\hline 7 & Strapack & Eksponensial & 2.26013 \\
\hline 8 & Packaging & Eksponensial & 14.0043 \\
\hline
\end{tabular}

Tabel 2

Hasil Pendugaan Awal Distribusi untuk Waktu Pelayanan Changing Tower ( menit )

\begin{tabular}{|c|l|l|l|}
\hline No & \multicolumn{1}{|c|}{ JENIS DATA } & $\begin{array}{c}\text { DISTRIBUSI } \\
\text { AWAL }\end{array}$ & - \\
\hline 1 & Pra-Strapack Center Panel & Eksponensial & 2.12825 \\
\hline 2 & Pra-Strapack Bass Assembly & Eksponensial & 1.28804 \\
\hline 3 & Pra-Strapack Door Panel & Eksponensial & 2.44896 \\
\hline 4 & Pra-Strapack Drawer Front & Eksponensial & 3.41329 \\
\hline 5 & Pra-Strapack Drawer Side, Back dan Base & Eksponensial & 5.39913 \\
\hline 6 & Hardware & Eksponensial & 4.89603 \\
\hline 7 & Strapack & Eksponensial & 5.18619 \\
\hline 8 & Packaging & Eksponensial & 4.04795 \\
\hline
\end{tabular}

\section{Analisa Antrian}

Parameter distribusi yang didapat dibagian packing ialah sebagai berikut :

Tabel 3

Nilai rata-rata Waktu Antar Kedatangan dan Pelayanan untuk Changing Tower

\begin{tabular}{|c|l|c|c|c|}
\hline No & \multicolumn{1}{|c|}{ Jenis Data } & $\begin{array}{c}\lambda \\
(\mathbf{k o m p} / \text { jam })\end{array}$ & $\begin{array}{c}\boldsymbol{\mu} \\
(\mathbf{k o m p} / \text { jam })\end{array}$ & $\boldsymbol{\rho}=\boldsymbol{\lambda} / \boldsymbol{\mu}$ \\
\hline 1 & PraStrapack Center Panel & 30.97 & 28.19 & 1.10 \\
\hline 2 & PraStrapack Bass Assembly & 48.59 & 46.58 & 1.04 \\
\hline 3 & PraStrapack Door Panel & 8.84 & 24.50 & 0.36 \\
\hline 4 & PraStrapack Drawer Front & 9.80 & 17.58 & 0.56 \\
\hline 5 & PraStrapack Drawer Side, Back dan Base & 19.22 & 11.11 & 1.73 \\
\hline 6 & Hardware & 11.47 & 12.25 & 0.94 \\
\hline 7 & Strapack & 26.55 & 11.60 & 2.29 \\
\hline 8 & Packaging & 4.28 & 14.82 & 0.29 \\
\hline
\end{tabular}


Kemudian variabel antrian yang berupa rate / laju kedatangan $\{\mathrm{E}(\mathrm{T})=1 / \lambda\}$ dan pelayanan $\{E(T)=1 / \mu\}$ serta intensitas aliran dapat dilihat pada tabel dibawah ini:

Tabel 4

Rate / laju kedatangan dan pelayanan

\begin{tabular}{|c|l|c|c|c|c|}
\hline No & \multicolumn{1}{|c|}{ Jenis Data } & $\boldsymbol{N} / \boldsymbol{\lambda}$ & $\boldsymbol{1} / \boldsymbol{\mu}$ & $\boldsymbol{\rho}=\boldsymbol{\lambda} / \boldsymbol{\mu}$ & Keterangan \\
\hline 1 & Pra-Strapack Center Panel & & & & \\
\hline 2 & Pra-Strapack Bass Assembly & 0.032 & 0.035 & 1.10 & Queue (antrian) \\
\hline 3 & Pra-Strapack Door Panel & 0.020 & 0.021 & 1.04 & Queue (antrian) \\
\hline 4 & Pra-Strapack Drawer Front & 0.113 & 0.041 & 0.36 & Steady State \\
\hline 5 & Pra-Strapack Drawer Side, Back dan Base & 0.102 & 0.057 & 0.56 & Steady State \\
\hline 6 & Hardware & 0.087 & 0.082 & 0.94 & Steady State \\
\hline 7 & Strapack & 0.038 & 0.086 & 2.29 & Queue (antrian) \\
\hline 8 & Packaging & 0.234 & 0.067 & 0.29 & Steady State \\
\hline
\end{tabular}

$\mathrm{E}_{\mathrm{C}}\left(\mathrm{n}_{\mathrm{t}}\right)-\mathrm{E}_{\mathrm{c}+1} \leq \mathrm{C} 1 / \mathrm{C} 2 \leq \mathrm{E}_{\mathrm{c}-1}\left(\mathrm{n}_{\mathrm{t}}\right)-\mathrm{E}_{\mathrm{c}}\left(\mathrm{n}_{\mathrm{t}}\right)$

Dari tabel 4 diatas, bahwa pada proses Pra Strapack Door panel, Drawer front, Hardware dan Packaging dalam keadaan steady state. Akan tetapi pada proses Pra Strapack Center Panel, Base Assembly, Drawer ( Side, Back, Base ) dan Strapack, mempunyai nilai $\rho>1$ yang berarti pada proses tersebut terjadi antrian dalam sistem sehingga pelayanan ( server ) sibuk. Untuk itu perlu ditambahkan jumlah server untuk mengurangi kepanjangan antrian.

Dengan menggunakan model keputusan dalam menentukan jumlah pelayan ( c ) yang optimum ditiap-tiap bagian packaging dengan menggunakan rumus (Siagian P, 1987, hal 440):
Nilai C1 / C2 menunjukkan dimana pencarian c dimulai.

Sehingga (Siagian P, 1987, hal 419):

$$
E\left(n_{t}\right)=f(b)\left(\frac{\lambda}{c \mu-\lambda}\right)+\frac{\lambda}{\mu}
$$

Dimana :

$$
\mathrm{Cl}=\text { Ongkos tiap pelayanan }
$$

tambahan persatuan waktu (Biaya Langsung)

$\mathrm{C} 2$ = Ongkos Tunggu (Biaya tak Langsung)

Nilai $\mathrm{fb}$ diperoleh dari tabel probability of busy period for $\mathrm{M} / \mathrm{M} / \mathrm{S}$ model 
A. Jumlah Server yang optimum

a Bagian Pra Strapack Center Panel

Tabel. 5

Jumlah Server untuk Center Panel

\begin{tabular}{|c|c|c|c|c|}
\hline $\mathrm{C}$ & $\begin{array}{c}\mathrm{Ec} \\
(\mathrm{nt})\end{array}$ & $\mathrm{E} \mathrm{c-1(nt)-Ec(nt)}$ & $\mathrm{C} 1 / \mathrm{C} 2=0.35$ & Keputusan \\
\hline 1 & $\sim$ & & & \\
\hline 2 & 1.58 & $\sim$ & & \\
\hline 3 & 1.17 & -0.41 & $\mathrm{C}=3$ & \\
\hline 4 & 1.10 & 0.07 & & \\
\hline
\end{tabular}

- Bagian Pra Strapack Base Assembly

Tabel 6

Jumlah server untuk Base Assembly

\begin{tabular}{|c|c|c|c|c|}
\hline $\mathrm{C}$ & $\mathrm{Ec}(\mathrm{nt})$ & $\mathrm{E} \mathrm{c}-1$ (nt) - Ec(nt) & $\mathrm{C1} / \mathrm{C} 2=0.35$ & Keputusan \\
\hline 1 & $\sim$ & & & \\
\hline 2 & 1.40 & $\sim$ & & \\
\hline 3 & 1.09 & 0.39 & $\mathrm{C}=3$ & \\
\hline 4 & 1.05 & 0.04 & & \\
\hline
\end{tabular}

ㅁ Bagian Strapack

Tabel. 7

Jumlah Server untuk Strapack

\begin{tabular}{|c|c|c|c|c|}
\hline$C$ & Ec (nt) & Ec-1(nt) - Ec(nt) & $\mathbf{C 1} / \mathbf{C} 2=0.35$ & Keputusan \\
\hline 1 & $\sim$ & & & \\
\hline 2 & $\sim$ & & & \\
\hline 3 & 4.20 & $\sim$ & & \\
\hline 4 & 2.63 & 1.57 & $C=5$ & \\
\hline 5 & 3.73 & 0.26 & & \\
\hline
\end{tabular}

B. Penentuan Waktu Tunggu Pada kondisi awal

Tabel 8

Waktu rata-rata menunggu dalam kondisi awal

\begin{tabular}{|c|l|c|c|c|}
\hline No & \multicolumn{1}{|c|}{ Bagian } & Model & W (jam) & Wq (jam) \\
\hline 1 & Pra Strapack Center Panel & $\mathrm{M} / \mathrm{M} / 1$ & 0.12 & 0.009 \\
\hline 2 & Pra Strapack Bass Assembly & $\mathrm{M} / \mathrm{M} / 1$ & 0.06 & 0.003 \\
\hline 3 & Pra Strapack Drawer Side, Back dan Base & $\mathrm{M} / \mathrm{M} / \mathrm{l}$ & 0.36 & 0.016 \\
\hline 4 & Strapack & $\mathrm{M} / \mathrm{M} / 4$ & 0.12 & 0.030 \\
\hline
\end{tabular}




\section{Penentuan Waktu Tunggu Pada kondisi akhir}

Tabel 9

Waktu menunggu rata-rata pada kondisi akhir

\begin{tabular}{|c|l|c|c|c|}
\hline No & \multicolumn{1}{|c|}{ Bagian } & Model & W (jam) & Wq (jam) \\
\hline 1 & Pra Strapack Center Panel & $\mathrm{M} / \mathrm{M} / 3$ & 0.04 & 0.003 \\
\hline 2 & Pra Strapack Bass Assembly & $\mathrm{M} / \mathrm{M} / 3$ & 0.02 & 0.001 \\
\hline 3 & Pra Strapack Drawer Side, Back dan Base & $\mathrm{M} / \mathrm{M} / 4$ & 0.09 & 0.004 \\
\hline 4 & Strapack & $\mathrm{M} / \mathrm{M} / 5$ & 0.10 & 0.0019 \\
\hline
\end{tabular}

\section{Penentuan Jumlah langganan ( $E(n t)$ atau $L$ )}

Tabel 10

Jumlah rata-rata langganan dalam sistem

\begin{tabular}{|c|l|c|c|}
\hline No & \multicolumn{1}{|c|}{ Bagian } & $\begin{array}{c}\text { E(nt) } \\
\text { Kondisi Awal }\end{array}$ & $\begin{array}{c}\text { E(nt) } \\
\text { kondisi Akhir }\end{array}$ \\
\hline 1 & Pra Strapack Center Panel & 11.44000 & 1.16465 \\
\hline 2 & Pra Strapack Bass Assembly & 24.17000 & 1.09688 \\
\hline 3 & Pra Strapack Drawer Side, Back dan Base & 2.37000 & 1.81718 \\
\hline 4 & Strapack & 2.63000 & 2.37016 \\
\hline
\end{tabular}

\section{KESIMPULAN}

Kesimpulan yang dapat diambil dari hasil pengolahan data adalah sebagai berikut

1. Operator yang didapatkan sesuai kebutuhan dengan biaya terendah di bagian Packing adalah :

- Pada kondisi awal didapatkan Total Cost sebesar Rp. 245.675.136 dengan jumlah server (operator) sebanyak 7.

- Pada kondisi akhir didapatkan Total Cost sebesar Rp. 67.193.922 dengan jumlah server (operator) sebanyak 15 .

2. Waktu tunggu yang didapatkan di Bagian Packing adalah :
- Pada kondisi awal didapatkan total waktu tunggu sebesar 39.60 menit

- Pada Kondisi akhir didapatkan total waktu tunggu sebesar 14.4 menit

Dengan demikian perusahaan akan mendapat tambahan keuntungan sebesar Rp. 177.471.214 tiap harinya dari selisih antara total cost pada kondisi awal sebesar Rp. 245.675.136 dengan jumlah operator sebanyak 7 dan pada kondisi akhir total cost sebesar Rp. 67.193.922 dengan jumlah operator sebanyak 15. Sehingga waktu tunggu juga mengalami penurunan sebesar 25.20 menit dari kondisi awal 39.6 menit dan kondisi akhir sebesar 14.4 menit. 


\section{DAFTAR PUSTAKA}

Djarwanto, PS Drs “ Statistik non

Parametrik" (edisi ke tiga), Dosen FE

Universitas Sebelas Maret Surakart, Yogjakarta BPFE.

Lieberman, Geraldi “Introduction to

Operation Research " (Fifth edition)

Mc Grawhill Internasional edition.

Siagian P, 1987, “Penelitian Operasional

Teori dan Praktek", Jakarta UI Press.

Subagya Pangestu, Drs MBA 1983,

Dasar-dasar Penelitian Research"

(edisi kedua) Yogjakarta, BPFE.
Tharliah, Tjujhu D. dan Ahmad D, 1992, “

Operation Research Model Pengambil keputusan " Sinar Baru Algensindo.

Thaha, Hamdy A, 1996, "Riset operasi suatu pengantar" (edisi kelima), Bina Rupa Aksara, Jakarta.

Walpole, RE, 1995, "Imu Peluang dan Statistika untuk Insinyur dan Ilmuwan", Jakarta.

WignjoSoebroto, S, 1995, “Ergonomi Studi Gerak dan Waktu" PT Guna Widya Jakarta. 